\section{Funding sources}

There are no sources of funding to declare.

\section{References}

1. Siebler T, Robson H, Shalet SM, Williams GR. Dexamethasone inhibits and thyroid hormone promotes differentiation of mouse chondrogenic ATDC5 cells. Bone. 2002;31(4):457-64.

2. Hant FN, Bolster MB. Drugs that may harm bone: Mitigating the risk. Cleve Clin J Med. 2016;83(4):281-8.

3. Hartmann K, Koenen M, Schauer S, Wittig-Blaich $\mathrm{S}$, Ahmad M, Baschant $\mathrm{U}$, et al. Molecular Actions of Glucocorticoids in Cartilage and Bone During Health, Disease, and Steroid Therapy. Physiol Rev. 2016;96(2):409-47.

4. Loi F, Cordova LA, Pajarinen J, Lin TH, Yao Z, Goodman SB. Inflammation, fracture and bone repair. Bone. 2016;86:119-30.

5. Kurmis AP, Kurmis TP, O'Brien JX, Dalen T. The effect of nonsteroidal anti-inflammatory drug administration on acute phase fracture-healing: a review. J Bone Joint Surg Am. 2012;94(9):815-23.

6. Zimmermann EA, Gludovatz B, Schaible E, Busse B, Ritchie RO. Fracture resistance of human cortical bone across multiple length-scales at physiological strain rates. Biomaterials. 2014;35(21):5472-81.
7. Nair AK, Gautieri A, Chang SW, Buehler MJ. Molecular mechanics of mineralized collagen fibrils in bone. Nat Commun. 2013;4:1724.

8. Derry S, Conaghan P, Da Silva JA, Wiffen PJ, Moore RA. Topical NSAIDs for chronic musculoskeletal pain in adults. Cochrane Database Syst Rev. 2016;4:CD007400.

9. Moghadam-Kia S, Werth VP. Prevention and treatment of systemic glucocorticoid side effects. Int $\mathrm{J}$ Dermatol. 2010;49(3):239-48.

10. Benkhadra K, Mohammed K, Al Nofal A, Carranza Leon BG, Alahdab F, Faubion S, et al. Menopausal Hormone Therapy and Mortality: A Systematic Review and Meta-Analysis. J Clin Endocrinol Metab. 2015;100(11):4021-8.

11. Russo CR. The effects of exercise on bone. Basic concepts and implications for the prevention of fractures. Clin Cases Miner Bone Metab. 2009;6(3):223-8.

12. Santos L, Elliott-Sale KJ, Sale C. Exercise and bone health across the lifespan. Biogerontology. 2017;18(6):931-946.

13. Jing D, Hao J, Shen Y, Tang G, Li ML, Huang SH, et al. The role of microRNAs in bone remodeling. Int $\mathrm{J}$ Oral Sci. 2015;7(3):131-43.

Acceptance for editing: 2019-11-09 Acceptance for publication: 2019-12-30 


\title{
Comparison of the effects of endurance and endurance-strength training programmes on the level of endothelial dysfunction in women with abdominal obesity: study protocol for a randomised controlled trial
}

Małgorzata Jamka ${ }^{1, a}$, Paweł Bogdański ${ }^{2, b}$, Patrycja Krzyżanowska-Jankowska, c , Joanna Karolkiewicz ${ }^{3, \mathrm{~d}}$, Radosław Mądry ${ }^{4, \mathrm{e}}$, Aleksandra Lisowska, ${ }^{1, \mathrm{f}}$, Jarosław Walkowiak ${ }^{1, g, *}$, Edyta Mądry ${ }^{5, \mathrm{~h}}$

${ }^{1}$ Department of Pediatric Gastroenterology and Metabolic Diseases, Poznan University of Medical Sciences, Poland

${ }^{2}$ Department of Treatment of Obesity, Metabolic Disorders and Clinical Dietetics, Poznan University of Medical Sciences, Poland

${ }^{3}$ Department of Physiology, Biochemistry and Hygiene, Poznań University School of Physical Education, Poland

${ }^{4}$ Department of Oncology, Poznan University of Medical Sciences, Poland

${ }^{5}$ Department of Physiology, Poznan University of Medical Sciences, Poland

* Corresponding Autor: Jarosław Walkowiak, MD, PhD; Department of Paediatric Gastroenterology and Metabolic Diseases, Poznan University of Medical Sciences, 27/33 Szpitalna Street, 60-572 Poznań, Poland; phone: +48618491432; fax: +48618472685; email: jarwalk@ump.edu.pl

a (iD) https://orcid.org/0000-0002-0257-6180

b (iD) https://orcid.org/0000-0002-0563-1624

c (iD) https://orcid.org/0000-0001-8676-9803

d (iD) https://orcid.org/0000-0002-7176-5540 e (iD https://orcid.org/0000-0003-0738-2788

$f$ (iD https://orcid.org/0000-0002-5453-4716

$g$ (iD https://orcid.org/0000-0001-5813-5707

h (iD https://orcid.org/0000-0002-0081-6558

\begin{abstract}
The primary objective of the study is to compare the effect of endurance and endurance-strength training on endothelial function in women with abdominal obesity. The secondary objectives include the assessment of the effect of both types of training on anthropometric, densitometric and biochemical parameters. In total, at least 100 women will be recruited for the study. The study population will be randomly divided into two groups according to the type of training: endurance and endurance-strength training. During the 3-month of intervention, both groups will be performed three times a week training of an equal exercise volume and duration of 60 minutes. Before and after the intervention selected anthropometric and densitometric parameters will be measured and body composition will be analysed. In addition, biochemical parameters related to glucose and insulin homeostasis, lipid metabolism, antioxidant status, oxidative stress, inflammatory markers and endothelial function will be assessed.
\end{abstract}

Keywords: endurance training; endurance-strength training; endothelial function; cardiovascular risk.

\section{Research Project Objectives}

The primary aim of the study is to assess the effect of endurance and endurance-strength training on endothelial function in women with abdominal obesity. The secondary aims include the assessment of the effect of both types of training on anthropometric parameters, body composition, 
densitometric parameters, glucose and insulin homeostasis, lipid metabolism, oxidative stress, antioxidant status and inflammatory markers.

\section{Research Plan and Basic Concept}

\section{Basic Concept}

It is well known that excessive body weight increases the progression of atherosclerosis [1]. One of the indicators of atherosclerosis is endothelial dysfunction which is also an independent risk factor for cardiovascular diseases [2, 3]. Several, albeit not all, studies have shown that regular physical activity may reduce the risk of atherosclerosis by the improvement of endothelial function [4, 5]. Regular training has also been shown to have other health-promoting properties such as: weight reduction, lowering blood pressure, improving lipid profile and glucose-insulin metabolism [4].

Current guidelines suggest that endurance training should be recommended for obese subjects [6-9]. It has been shown that this type of exercise has a beneficial effect on the reduction of body weight and improves cardiometabolic parameters [10]. On the other hand, strength training also contributes to the reduction in body weight, has a positive effect on body composition and reduces the risk of metabolic abnormalities related to obesity $[10,11]$. Therefore, we suppose that the implementation of strength components for endurance training might intensify the beneficial effects of physical activity. However, results of studies comparing the effect of endurance and endurance-strength training on cardiovascular risk and endothelial function parameters are equivocal [10-12]. Therefore, randomised controlled trials are needed, which would compare the effects of endurance and endurance-strength training in obese subjects.

\section{Study population}

Adult women with abdominal obesity will be recruited to the study. The inclusion and exclusion criteria are presented in Table 1. The study population will be informed that participation is voluntary and that each participant can withdraw at any time without providing reasons, as well as all the subjects will receive the detailed information about the study protocol. Written informed consent will be obtained from all participants. The present study will be conducted according to the guidelines of the Declaration of Helsinki. The protocol was approved by the Ethics Committee of the Poznan University of Medical Sciences (refs. 1077/12 with supplement 753/13).

\section{Study design}

The study is designed as a prospective randomised trial. Subjects will be randomly divided into two groups: endurance and endurance-strength training, using a randomisation

Table 1. The inclusion and exclusion criteria

\begin{tabular}{|c|c|}
\hline Inclusion criteria & Exclusion criteria \\
\hline $\begin{array}{l}\text { - Age } 50-60 \text { years } \\
\text { - Obesity (body mass } \\
\text { index (BMI) } \geq 30 \mathrm{~kg} / \mathrm{m}^{2} \text { ) } \\
\text { - Waist circumference > } \\
80 \mathrm{~cm} \\
\text { - A percentage of body } \\
\text { fat assessed by } \\
\text { bioimpedance } \geq 33 \% \\
\text { - Stable body weight in } \\
\text { the month prior to the } \\
\text { trial }\end{array}$ & $\begin{array}{l}\text { - Secondary form of obesity } \\
\text { - Secondary form of hypertension } \\
\text { - Type } 2 \text { diabetes mellitus } \\
\text { - History of coronary artery disease } \\
\text { - Stroke } \\
\text { - Congestive heart failure, clinically significant arrhythmias or conduction disorders } \\
\text { - Malignancy } \\
\text { - History of use of any dietary supplements within } 3 \text { months before the study } \\
\text { - Poorly controlled hypertension (mean systolic blood pressure > } 140 \text { mmHg and/or mean diastolic } \\
\text { blood pressure > } 90 \text { mmHg) during the month prior to the trial and/or necessity to modify } \\
\text { antihypertensive treatment in the last } 3 \text { months } \\
\text { - Lipid disorders requiring the implementation of drug treatment in the last } 3 \text { months } \\
\text { - Abnormal liver, kidney, or thyroid gland function } \\
\text { - Clinically significant acute or chronic inflammatory process within the respiratory, digestive or } \\
\text { genitourinary tract or in the oral cavity, pharynx or paranasal sinuses or connective tissue disease } \\
\text { or arthritis } \\
\text { - History of infection in the month } \\
\text { - Nicotine, alcohol or drug abuse } \\
\text { - Pregnancy or childbirth at enrolment or in the } 3 \text { months before enrolment, breast-feeding in the } 3 \\
\text { months prior to enrolment } \\
\text { - Any other condition that would make participation not in the best interest of the subject, or could } \\
\text { prevent, limit or confound the efficacy of the study }\end{array}$ \\
\hline
\end{tabular}




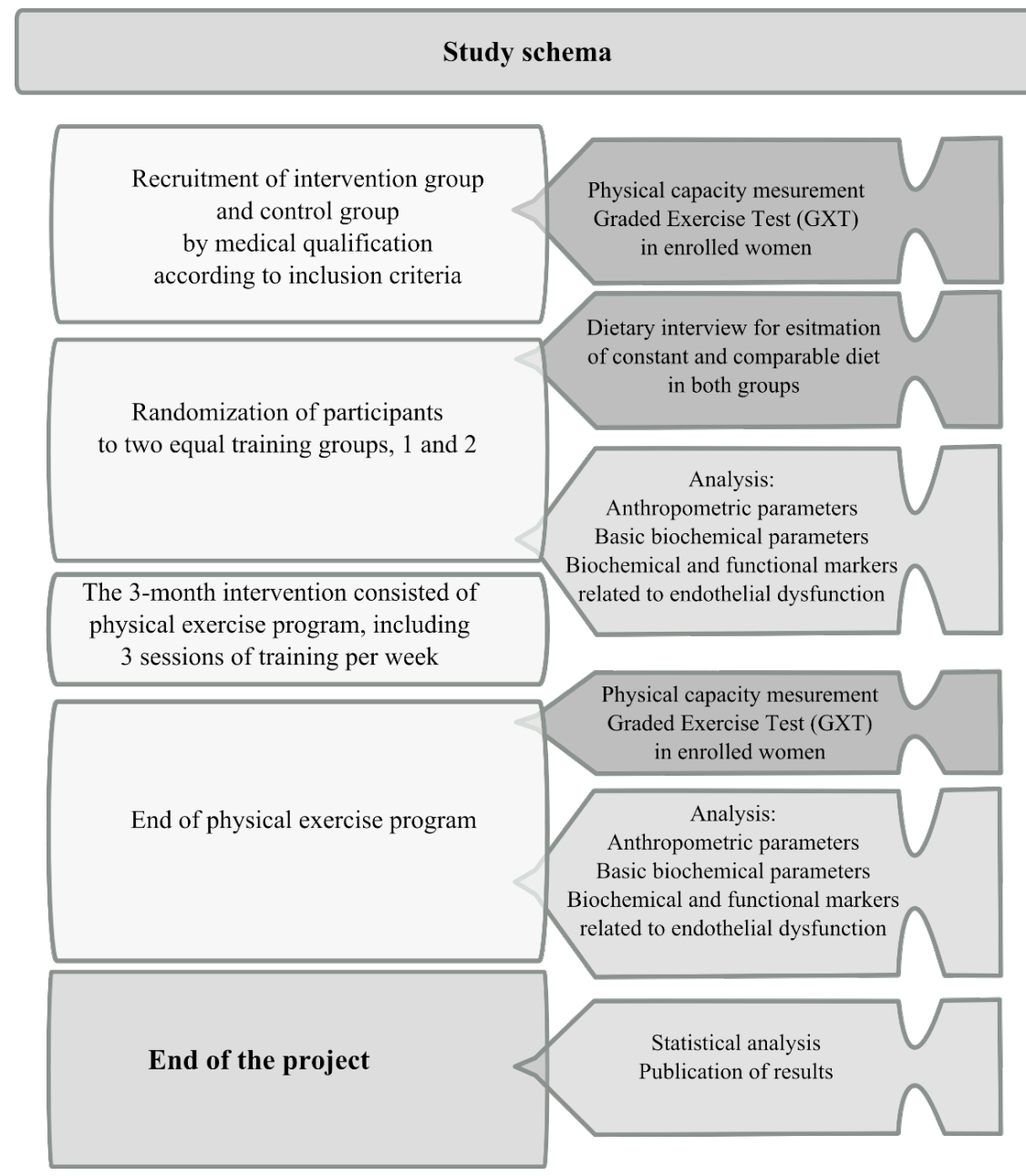

Figure 1. Scheme of the study

list. Both groups will perform 3-month of physical training which will vary only in the nature of the effort but have a comparable exercise volume. Aside from the training, all subjects will be instructed to maintain the physical activity and they dietary habits as they have previously led. At the baseline and after the 3-month of intervention anthropometric parameters, body composition, densitometric parameters, markers of endothelial function, oxidative stress, antioxidant status and inflammatory markers, as well as glucose and insulin homeostasis and lipid metabolism will be assessed. The scheme of the study is presented in Figure 1.

\section{Intervention}

The 3-month intervention will consist of a physical exercise programme, including three sessions of training per week. The training will be performed under the supervision of a qualified and certified fitness instructor and medical supervi- sion. A single workout will last 60 minutes The endurance group will undergo training on cycle ergometers (Schwinn Evolution, Schwinn Bicycle Company, Boulder, Colorado, USA). Training sessions will consist of 5 minutes of warm-up, 45 minutes of training at an intensity between $50-70 \%$ of maximum heart rate (HR), 5 minutes of cycling without load and 5 minutes of closing stretching and breathing exercises. Similarly, endurance-strength training will consist of 5 minutes of warm-up, 20 minutes of strength exercises at $50-60 \%$ of one repetition maximum, 25 minutes of endurance exercises on cycle ergometers (Schwinn Evolution, Schwinn Bicycle Company, Boulder, Colorado, USA) of intensity between $50-70 \%$ of maximum HR, 5 minutes of cycling without load and 5 minutes of closing exercises. The strength component will involve exercises with a neck barbell and a gymnastic ball. The general scheme of the training plan is presented in Figure 2. 


\section{Research Methodology}

\section{Graded Exercise Test (GXT)}

To determine the subjects' physical capacity, GXT will be performed at the beginning of the intervention on an electronically braked cycle ergometer (Kettler DX1 Pro, Ense-Parsit, Germany). GXT will begin at a work rate of $25 \mathrm{~W}$. The work rate will be incremented by $25 \mathrm{~W}$ every 2 minutes until the subject could no longer maintain the required pedal cadence. Expired gases and minute ventilation will be monitored continuously with an automated system (Oxycon Mobile; Viasys Healthcare, Hoechberg, Germany). Oxygen intake $\left(\mathrm{VO}_{2}\right)$ and carbon dioxide output $\left(\mathrm{VCO}_{2}\right)$ will be measured. $\mathrm{VO}_{2}$ peak, HR peak, time to exhaustion and maximal work rate will be assessed. To determine the ventilatory threshold, the V-slope method and the ventilatory equivalent method will be used.
Physiological parameters and markers related to the function of endothelium

Blood pressure will be measured at baseline and after the intervention period according to guidelines of the European Society of Hypertension [13]. Artery flow mediated dilatation will be assessed. Pulse wave analysis will be performed by SphygmoCor system (EINST Technology Pte Ltd., Singapore).

\section{Anthropometry parameters}

Anthropometry parameters (body weight, body height, waist and hip circumferences) will be measured [14] and BMI will be calculated before and after the intervention period [15]. In this study, abdominal obesity will be recognised according to the International Diabetes Federation criteria with a waist circumference exceeding $80 \mathrm{~cm}$ in women [16].

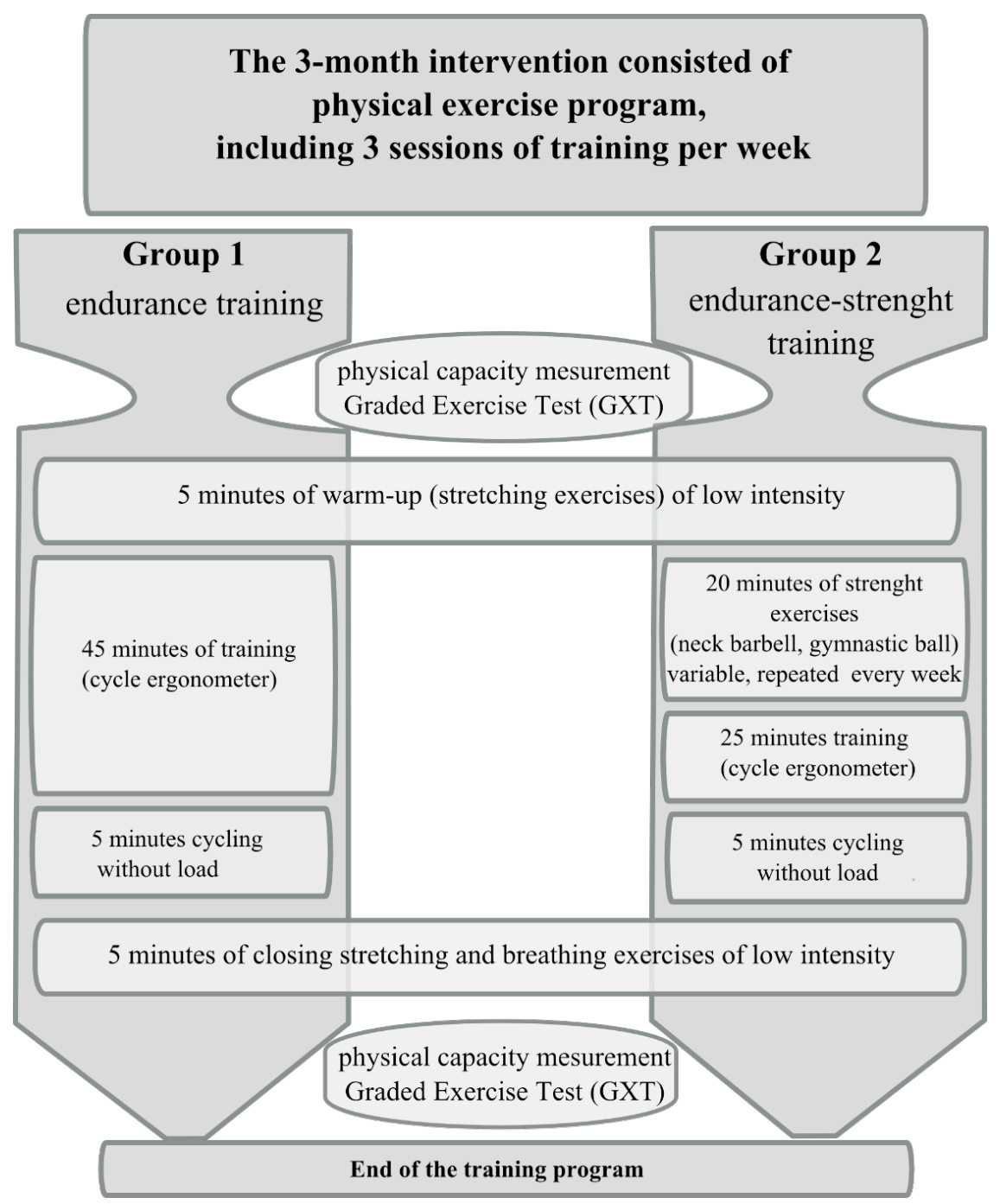

Figure 2. Scheme of a single training session 
Body composition

Body composition will be assessed by bioelectrical impedance analysis with InBody 370 analyser (InBody Co. Ltd., Seoul, South Korea) during the recruitment process to check if subjects meet the inclusion criteria [17].

\section{Densitometry}

At baseline and after the intervention period densitometric measurement will be performed using Dual X-Ray Absorptiometry (Hologic Discovery QDR). The assessment will be carried out in accordance with the methodology recommended by the International Society for Clinical Densitometry [18]. Body composition (fat mass and free-fat mass) will be assessed for total body and separately for each part of the body. Visceral adipose tissue will be measured. Appendicular lean mass index and lean mass index will be calculated. Bone mineral content and bone mineral density will be assessed for the whole skeleton and additionally at the lumbar (L1-L4) spine and hip regions.

\section{Biochemical measurements}

Fasting blood samples will be collected from all study participants before and after the intervention period. Markers of endothelial function, glucose and insulin homeostasis, lipid metabolism. oxidative stress, antioxidant status and inflammation will be analysed by standard clinical chemical assays (see Supplementary Table 1).

\section{Measurable Effects}

Data from this study will potentially provide additional information that allows more efficient and precise planning of training regimes for obese subjects and may result in, beyond body weight reduction, prevention of endothelial dysfunction and improvement of cardiovascular health.

\section{Expected Results}

Previous studies have shown that exercise may decrease the risk of cardiovascular disease by preventing endothelial dysfunction [19-21]. However, it is supposed that the beneficial effect of physical activity may depend on the intensity of training. While strenuous exercise increases oxidative stress, regular and moderate physical activity promotes an antioxidant state and preserves endothelial function [22]. It is also suggested that the effect of physical activity on endothelial function may also depend on the type of training. However, results of studies comparing the effects of endurance and strength training on endothelial function are conflicting. Schjerve et al. [10] observed that both types of training significantly improve endothelial function in obese subjects after 12 weeks of intervention. However, high-intensity aerobic training was more effective in the improvement of endothelial function compared with strength training and moderate-intensity groups. On the other hand, Rakobowchuk et al. [23] noted that 12 weeks of resistance training in healthy young men did not change endothelial function, but the increased arterial diameter and, hence, blood flow. Østergård et al. [24] also reported no changes in endothelial function after 10-week of aerobic training in obese subjects with type 2 diabetes.

We suppose that the implementation of strength components for endurance training might intensify the beneficial effects of physical activity. Comparison of the effects of endurance and endurance-strength training programmes on endothelial function and other metabolic parameters in obese women will allow to verify the hypothesis and will answer the question of which type of training is more effective in the improvement of endothelial function and cardio-metabolic parameters. In addition, the results of this study should give a better insight into the effect of endurance and endurance strength training on human health. The expected findings may enable to construct first special physical activity guidelines for obese subjects to prevent endothelial dysfunction.

\section{Acknowledgements}

E.M., M.J. \& J.W. wrote the manuscript. E.M., P.B., J.K. \& J.W. designed the study. J.K., P.B., R.M., A.L. \& P.K-J. edited the manuscript. All authors reviewed and approved the final manuscript.

\section{Conflict of interest statement}

The authors declare no conflict of interest.

\section{Funding sources}

This study was supported by the National Science Centre (JW - UMO-2014/13/B/NZ7/02209). Principal Investigator: Professor Jarosław Walkowiak, MD, PhD. Main Co-investigators: Edyta Mądry, MD, PhD., Professor Paweł Bogdański, MD, PhD; Joanna Karolkiewicz, MD, PhD. 
Supplementary Table 1. List of biochemical parameters that will be analysed in the study

\begin{tabular}{|c|c|}
\hline Parameter & Method of analysis \\
\hline \multicolumn{2}{|r|}{ Endothelial function } \\
\hline Asymmetric dimethylarginine (ADMA) & Immunoenzymatic method (SunRed Human (ADMA) ELISA Kit, China) \\
\hline Endothelial nitric oxide synthase (eNOS) & $\begin{array}{l}\text { Immunoenzymatic method (MyBioSource Human Endothelial Nitric Oxide Synthase } \\
\text { ELISA kit, US)A }\end{array}$ \\
\hline Homocysteine (Hcy) & Immunoenzymatic method (Axis Homocysteine EIA kit, United Kingdom) \\
\hline $\mathrm{NO}_{2}$ & Method described by Tsikas ${ }^{1}$ \\
\hline $\mathrm{NO}_{3}$ & Method described by Tsikas ${ }^{1}$ \\
\hline Plasminogen activator inhibitor-1 (PAI-1) & $\begin{array}{l}\text { Immunoenzymatic method (Human Total Serpin E1/PAI-1 Quantikine ELISA, R\&D } \\
\text { Systems a biotechne brand, USA) }\end{array}$ \\
\hline Vascular endothelial growth factor (VEGF) & $\begin{array}{l}\text { Immunoenzymatic method (Human VEGF, Quantikine ELISA, R\&D Systems } \\
\text { a biotechne brand, USA) }\end{array}$ \\
\hline \multicolumn{2}{|r|}{ Glucose and insulin homeostasis } \\
\hline Glucose & Enzymatic method with hexokinase \\
\hline Insulin & Electrochemiluminescence method \\
\hline Glycated haemoglobin (HbA1c) & Turbidimetric immunoinhibitory method in hemolysate prepared from blood \\
\hline Insulin-like growth factor (IGF-1) & Immunoenzymatic method (IGF-1 600 ELISA kit, DRG Intruments GmbH, Germany) \\
\hline \multicolumn{2}{|r|}{ Lipid metabolism } \\
\hline $\begin{array}{l}\text { Total cholesterol } \\
\text { (TC) }\end{array}$ & Enzymatic colorimetric method \\
\hline Low-density lipoprotein cholesterol (LDL-C) & Friedewald formula: LDL-C $=\mathrm{TC}-(\mathrm{HDL}-\mathrm{C}+\mathrm{TG} / 5)$ \\
\hline High-density lipoprotein cholesterol (HDL-C) & Homogeneous enzymatic colorimetric method \\
\hline Triglycerides (TG) & Enzymatic colorimetric method \\
\hline Oxidized low-density lipoprotein (ox-LDL) & Immunoenzymatic method (Human ox-LDL ELISA kit, SunRed, China) \\
\hline Apolipoprotein A1 (ApoA1) & Nephelometric method \\
\hline Apolipoprotein B (ApoB) & Nephelometric method \\
\hline Apolipoprotein E (ApoE) & Immunoenzymatic method (Human Apolipoprotein E ELISA Kit, Assaypro, USA) \\
\hline \multicolumn{2}{|r|}{ Oxidative stress } \\
\hline Advanced glycation end products (AGEs) & Immunoenzymatic method (Human AGEs ELISA Kit, MyBiosource, USA) \\
\hline \multicolumn{2}{|r|}{ Antioxidant status } \\
\hline Glutathione (GSH) & Immunoenzymatic method (Human Reduced GSH), ELISA Kit, MyBiosource, USA) \\
\hline Superoxide dismutase (SOD) & Colorimetric method (SOD Assay Kit, Cayman Chemical, USA) \\
\hline Total antioxidant status (TAS) & Immunoenzymatic method (Human TAS ELISA kit, Qayee-bio, China) \\
\hline Paraoxonases (PON) & Immunoenzymatic method (Human PON ELISA Kit, MyBiosource, USA) \\
\hline \multicolumn{2}{|r|}{ Inflammatory markers } \\
\hline High-sensitivity C reactive protein (hs-CRP) & Latex enhanced turbidimetric immunoassay method \\
\hline Interleukin-6 (IL-6) & $\begin{array}{l}\text { Immunoenzymatic method (Human IL-6 Immunoassay, Quantikine HS ELISA, R\&D } \\
\text { Systems a biotechne brand, USA) }\end{array}$ \\
\hline Interleukin-8 (IL-8) & $\begin{array}{l}\text { Immunoenzymatic method (Human CXCL8/IL-8 Immunoassay, Quantikine HS } \\
\text { ELISA, R\&D Systems a biotechne brand, USA) }\end{array}$ \\
\hline $\begin{array}{l}\text { Monocyte chemoattractant protein } 1 \\
\text { (MCP-1) }\end{array}$ & Immunoenzymatic method (MCP-1 human ELISA, DRG Intruments GmbH, Germany) \\
\hline Matrix metalloproteinase-2 (MMP-2) & $\begin{array}{l}\text { Immunoenzymatic method (Total MMP-2 Immunoassay, Quantikine ELISA, R\&D } \\
\text { Systems a biotechne brand, USA) }\end{array}$ \\
\hline Matrix metalloproteinase-9 (MMP-9) & $\begin{array}{l}\text { Immunoenzymatic method (Human MMP-9 Immunoassay, Quantikine ELISA, R\&D } \\
\text { Systems a biotechne brand, USA) }\end{array}$ \\
\hline Tumor necrosis factor- $a($ TNF- $a)$ & $\begin{array}{l}\text { Immunoenzymatic method (Human tumor necrosis factor alfa, ELISA kit, } \\
\text { Qayee-bio, China) }\end{array}$ \\
\hline
\end{tabular}

${ }^{1}$ Tsikas D. Simultaneous derivatization and quantification of the nitric oxide metabolites nitrite and nitrate in biological fluids by gas chromatography/mass spectrometry. Anal Chem. 2000 Sep;72(17):4064-4072. 


\section{References}

1. Lee S-Y, Chang H-J, Sung J, Kim KJ, Shin S, Cho I-J, et al. The impact of obesity on subclinical coronary atherosclerosis according to the risk of cardiovascular disease. Obesity. 2014 Jul;22(7):1762-1768.

2. Vanhoutte PM, Shimokawa H, Tang EHC, Feletou M. Endothelial dysfunction and vascular disease. Acta Physiol. 2009 Jun;196(2):193-222.

3. Matsuzawa Y, Lerman A. Endothelial dysfunction and coronary artery disease: assessment, prognosis, and treatment. Coron Artery Dis. 2014 Dec;25(8):713-724.

4. Lippincott MF, Desai A, Zalos G, Carlow A, De Jesus $\mathrm{J}$, Blum A, et al. Predictors of endothelial function in employees with sedentary occupations in a worksite exercise program. Am J Cardiol. 2008 Oct;102(7):820824.

5. Duncker DJ, Bache RJ. Regulation of coronary blood flow during exercise. Physiol Rev. 2008 Jul;88(3):1009-1086.

6. Jensen MD, Ryan DH, Apovian CM, Ard JD, Comuzzie AG, Donato KA, et al. 2013 AHA/ACC/TOS guideline for the management of overweight and obesity in adults: a report of the American College of Cardiology/American Heart Association Task Force on Practice Guidelines and The Obesity Society. Circulation. 2014 Jun;129(25 Suppl 2):S102-S138.

7. Donnelly JE, Blair SN, Jakicic JM, Manore MM, Rankin JW, Smith BK, et al. Appropriate physical activity intervention strategies for weight loss and prevention of weight regain for adults. Med Sci Sport Exerc. 2009 Feb;41(2):459-471.

8. Jakicic JM, Clark K, Coleman E, Donnelly JE, Foreyt J, Melanson E, et al. American College of Sports Medicine position stand. Appropriate intervention strategies for weight loss and prevention of weight regain for adults. Med Sci Sports Exerc. 2001 Dec;33(12):21452156.

9. Fogelholm M, Stallknecht B, Van Baak M. ECSS position statement: exercise and obesity. Eur J Sport Sci. 2006 Aug;6(1):15-24.

10. Schjerve IE, Tyldum GA, Tjønna AE, Stølen T, Loennechen JP, Hansen HEM, et al. Both aerobic endurance and strength training programmes improve cardiovascular health in obese adults. Clin Sci. 2008 Nov;115(9):283-293.

11. Ho SS, Dhaliwal SS, Hills AP, Pal S. The effect of 12 weeks of aerobic, resistance or combination exercise training on cardiovascular risk factors in the overweight and obese in a randomized trial. BMC Public Health. 2012 Aug;12(1):704.

12. Azarbayjani M, Abedi B, Peeri M, Stannard SR. Effects of combined aerobic and resistant training on lipid profile and glycemic control in sedentary men. Int Med J. 2014 Apr;21(2):132-136.

13. Parati G, Stergiou GS, Asmar R, Bilo G, de Leeuw P, Imai $Y$, et al. European Society of Hypertension guide- lines for blood pressure monitoring at home: a summary report of the Second International Consensus Conference on Home Blood Pressure Monitoring. J Hypertens. 2008 Aug;26(8):1505-26.

14. National Health and Nutrition Examination Survey (NHANES). Anthropometry procedures manual. 2007. Accessed: 15.09.2019. Online: https://www.cdc.gov/ nchs/data/nhanes/nhanes_07_08/manual_an.pdf.

15. World Health Organization. Global database on body mass index. World Health Organization; 2006. Accessed: 15 Dec 2018. Online: https://www.who.int/ nutrition/databases/bmi/en/.

16. International Diabetes Federation. The IDF consensus worldwide definition of the metabolic syndrome. Belgium: International Diabetes Federation; 2006.

17. Kyle U, Bosaeus I, De Lorenzo AD, Deurenberg P, Elia $M$, Gómez JM, et al. Bioelectrical impedance analysis? Part I: review of principles and methods. Clin Nutr. 2004 Oct;23(5):1226-1243.

18. Hangartner TN, Warner S, Braillon P, Jankowski $L$, Shepherd J. The official positions of the International Society for Clinical Densitometry: acquisition of dual-energy X-ray absorptiometry body composition and considerations regarding analysis and repeatability of measures. J Clin Densitom. 2013 Oct-Dec;16(4):520-536.

19. Edwards DG, Schofield RS, Lennon SL, Pierce GL, Nichols WW, Braith RW. Effect of exercise training on endothelial function in men with coronary artery disease. Am J Cardiol. 2004 Mar;93(5):617-620.

20. Cohen ND, Dunstan DW, Robinson C, Vulikh E, Zimmet PZ, Shaw JE. Improved endothelial function following a 14-month resistance exercise training program in adults with type 2 diabetes. Diabetes Res Clin Pract. 2008 Mar;79(3):405-411.

21. Beck DT, Martin JS, Casey DP, Braith RW. Exercise training improves endothelial function in resistance arteries of young prehypertensives. J Hum Hypertens. 2014 May;28(5):303-309.

22. Di Francescomarino S, Sciartilli A, Di Valerio V, Di Baldassarre A, Gallina S. The effect of physical exercise on endothelial function. Sport Med. 2009 Oct;39(10):797-812.

23. Rakobowchuk M, McGowan CL, de Groot PC, Hartman JW, Phillips SM, MacDonald MJ. Endothelial function of young healthy males following whole body resistance training. J Appl Physiol. 2005 Jun;98(6):21852190.

24. Østergård T, Nyholm B, Hansen TK, Rasmussen LM, Ingerslev J, Sørensen KE, et al. Endothelial function and biochemical vascular markers in first-degree relatives of type 2 diabetic patients: the effect of exercise training. Metabolism. 2006 Nov;55(11):1508-1515.

Acceptance for editing: 2019-11-09 Acceptance for publication: 2019-12-30 